\title{
JURISPRUDÊNCIA COMO FONTE DE DIREITO NA TEORIA DE SISTEMAS SOCIAIS AUTOPOIÉTICOSO ${ }^{i}$
}

Willis Santiago Guerra Filho ${ }^{\mathrm{ii}}$

\section{Resumo}

A teoria dos modelos, proposta por Miguel Reale para substituir com vantagens a vetusta doutrina das fontes, foi incorporada à perspectiva sistêmica luhmanniana. Para atender à condição cognitiva necessária à autorreflexão e à autoprodução do Direito, porém, os modelos jurídicos devem ser concebidos como modelos internos do sistema, isto é, construtores de uma realidade especificamente jurídica, com o que não se coaduna a distinção feita por Reale entre "modelos jurídicos" e "modelos dogmáticos", onde estes últimos seriam modelos "criados" pela teoria do direito, enquanto aqueles seriam propriamente normativos. A autonomia do Direito, portanto, resulta não apenas da autoprodução de suas normas, mas também da autoconstituição de figuras jurídico-dogmáticas, que permitam reformular, em termos especificamente jurídicos, a percepção de uma problemática extrajurídica (econômica, política, moral etc.).

Palavras-chave: Teoria dos Modelos. Teoria dos Sistemas. Fonte de Direito.

${ }^{\mathrm{i}}$ Professor titular do Centro de Ciências Jurídicas e Políticas da Universidade Federal do Estado do Rio de Janeiro (UNIRIO). Doutor em Ciência do Direito pela Universidade de Bielefeld, Alemanha. Livre-Docente em Filosofia do Direito pela Universidade Federal do Ceará (UFCE). Doutor e PósDoutor em Filosofia pela Universidade Federal do Rio de Janeiro (UFRJ). Professor Doutor do Departamento de Teoria Geral do Direito da Pontifícia Universidade Católica de São Paulo (PUC/SP). Coordenador do Núcleo de Pesquisa em Teoria Social, Metodologia, Lógica e Semiótica do Direito no Programa de Estudos Pós-Graduados em Direito da PUC/SP. 


\begin{abstract}
The theory of legal models were proposed by Miguel Reale to substitute the archaic doctrine of legal sources and was adopted by the Luhmannian systemic approach. But in order to attain the cognitive condition necessary to Law's self-reflection and self-production the legal models must be conceived as internal to the legal system, that is to say, as builders of a specific juridical reality, so that it is not acceptable the distinction between the models made by legal theory and those properly normatives. Law's autonomy, then, results not only of the self-production of its norms, but also from the self-constitution of dogmatic figures, which make possible to reformulate, in specific legal terms, the perception of not-legal issues (economic, political, moral etc.).
\end{abstract}

Keywords: Models Theory. Systems Theory. Law Source.
$\mathrm{E}$ m "O Direito da Sociedade", Luhmann refere, em diversos momentos, a noção de fonte do direito no contexto da definição da validade do Direito; em uma delas ${ }^{1}$, já no final da obra, caracteriza-a como uma metáfora que tem a função, no sistema jurídico, de uma "fórmula de contingência", assim como Deus no sistema da religião ${ }^{2}$, ou a justiça (material) para o jusnaturalismo (racional). Isso significa, como ele próprio explica, que por meio de tal (ou tais) fórmula(s) o que parece arbitrário a um observador externo ao(s) sistema(s) - ou, em seus próprios termos, artificial e contingente - "aparece como natural e necessário" de um ponto de vista interno, apto a permitir o desdobramento de cadeias argumentativas para além da tautologia que define o direito válido, como o que é definido como tal pelo direito. Criam-se, assim, condições para que se indique, concretamente, dentre as diversas possibilidades de validação como direito, o que se pressupõe como posto, mas que de fato ainda está para se pôr, aquela que em dada circunstância haverá de ser tida como "lícita" (Recht), lançando as demais possibilidades para o campo da ilicitude (Unrecht), sem com isso cancelá-las enquanto possibilidades, que até podem ter sido distinguidas de outras que não teriam ainda sido divisadas, justamente ao serem negadas. E esta é uma função desempenhada internamente ao sistema jurídico pela unidade judicial, a que tem controle sob o código binário específico deste sistema, do tipo de comunicação que ele administra, que é aquele do lícito/ilícito (Recht/Unrecht).

O papel do Judiciário em um Estado que se quer democrático, vale destacar, é distinto daquele que se lhe atribui na formulação clássica sobre suas relações com os demais poderes estatais. Do Judiciário, hoje, não é de se esperar uma posição subalterna frente a esses outros poderes, a quem caberia a produção normativa. O juiz não há de se limitar a ser apenas, como disse Montesquieu, la bouche de la loi, mas sim la bouche $d u$ droit, isto é, a boca não só da lei, mas do próprio Direito. Sobre esse ponto, aliás,

${ }^{1}$ LUHMANN, Niklas. Das recht der gesellschaft. Frankfurt am Main, 1993, p. 526.

${ }^{2}$ LUHMANN, Niklas. Die religion der gesellschaft. In: KEISERLING, A. (Ed.). Frankfurt am Main, 2002, p. 147 ss. 
explicitou a jurisprudência constitucional alemã, que a Lei Fundamental, quando estabelece, em seu art. 97, que o juiz está vinculado apenas à lei, essa vinculação deve ser entendida como ao Direito $^{3}$. Nesse sentido, a indeterminação e a subjetividade das decisões judiciais (tanto que elas podem ser baseadas em diversos sentidos plausíveis, muitos até mesmo em oposição), apontadas por D. Kennedy e o chamado critical legal studies mouvement em geral, não levam, como ele declara, ao "não fechamento do acordo dos sistemas jurídicos a respeito de seu próprio critério"4. Isso aconteceria se nós estivéssemos representando um "sistema alopoiético (= não autopoiético)".

Em um sistema jurídico autopoiético o resultado de uma decisão judicial tem sempre a natureza de uma declaração de validade prima facie, sobre o que tem de ser considerado "direito", "lícito" (Recht) no sistema, uma vez que o sistema, ele mesmo, é a condição de sua validade $(\text { Geltung })^{5}$. Aqui temos também de lembrar a observação feita por Trubek ${ }^{6}$, de que "a mais avançada destas ideias pós-modernas difunde-se na cultura legal quanto mais começamos a ver o Direito não como um conjunto de comandos determinados, ou mesmo como um conjunto de normas 'contraditórias mas ainda estruturadas', princípios, e visões, mas até certo ponto como uma série de fragmentos, os quais são dispostos, no entanto, em uma larga cadeia de processos e práticas localizadas". Esses processos podem ser vistos como o meio de circulação de comunicação no sistema jurídico. O significado disso ficará mais claro adiante, após a apresentação da teoria do direito como sistema autopoiético.

A atividade judicial não se reduz a mera aplicação de Direito preexistente, sendo, na verdade, criativa, produtora de direito, como se evidencia mesmo na tão atacada doutrina kelseniana, onde a sentença aparece como uma norma jurídica, diversa daquelas gerais e abstratas em que costuma se basear, e o ato de interpretação e aplicação do Direito pelo juiz como integrante da política do direito (Rechtspolitik), ao importar na opção por algum dos valores objetivamente consagrados nas normas positivas. Mais esclarecedora ainda sobre a posição dos órgãos jurisdicionais no sistema jurídico é a última versão da teoria de Luhmann ${ }^{7}$.

O sistema jurídico aparece como um dos "sistemas funcionais" do sistema social global, com a tarefa de reduzir a complexidade do ambiente, absorvendo a (dupla) contingência do comportamento social, ao garantir certa congruência entre as expectativas mútuas de como os indivíduos vão se comportar (incluindo a interpretação de como uma expectativa será entendida pelo outro), e a generalização dessas expectativas, pela imunização do perigo de decepcionarem-se. Daí ser o Direito definido, na teoria sociológica luhmanniana, como "generalização congruente de expectativas comportamentais”, generalização esta que fornece "uma imunização simbólica de expectativas contra outras possibilidades" 8 sistema jurídico, para Luhmann, coerentemente, integra o "sistema imunológico" das sociedades, imunizando-as de conflitos entre seus membros, surgidos já em outros sistemas sociais (político, econômico, familiar educacional etc.). Isso, porém, é feito não pela negação dos conflitos, isto é, contra os conflitos, e sim com os conflitos, assim como os sistemas vivos se imunizam das doenças com seus germes. Para tanto, a complexidade da realidade social, com sua extrema contingência, é reduzida pela construção de uma "para-realidade", codificada a partir do esquematismo binário "Direito/não Direito" (ou "lícito/ilícito" - Recht/Unrecht), onde se preveem os conflitos

\footnotetext{
${ }^{3}$ HESSE, Konrad. Grundzüge des verfassungsrechts der bundesrepublik deutschland. 14th. ed. Heidelberg, 1984, p. 210, nota 54.

${ }^{4}$ KENNEDY, Duncan. The role of law in economic thought: essays on the fetishism of commodities. The American University Law Review, n. 34, 1985. p. 999. Ver também: JOERGES, Christian. Politische Rechtstheorie and critical legal studies: points of contact and divergencies. In: (Ed.). Critical legal thought: an american-german debate. Baden-Baden, 1989.

${ }^{5}$ Ver LUHMANN, Niklas. Die Geltung des Rechts. Rechtstheorie, Berlin, n. 22, 1991, p. 278.

${ }^{6}$ TRUBEK, David M. Back to the future: the short, happy life of the law and society movement. Florida State University Law Review, Miami, n. 18, 1990, p. 43.

${ }^{7}$ Conforme, resumidamente, as seguintes obras: LUHMANN, Niklas. Die stellung der gerichte im rechtssystem. Rechtstheorie, Berlin, n. 21, 1990; LUHMANN, Niklas. A posição dos tribunais no sistema jurídico. AJURIS, Porto Alegre, n. 49, 1990.

${ }^{8}$ LUHMANN, Niklas. Rechtssoziologie. Reinbeck bei Hamburg, 1972. v. I. p. 94. Trad. bras. Sociologia do Direito I. G. Bayer (trad.). Rio de Janeiro, 1983. v. II, p. 110.
} 


\subsection{TEORIA SOCIOJURÍDICA NACIONAL}

que são conflitos para o Direito e se oferecem as soluções que são conformes ao Direito ${ }^{9}$.

Roth $^{10}$ mostra que essa construção de uma para-realidade, uma Wirklichkeit, de complexidade reduzida, em cima da realidade propriamente dita, a Realität, é feita já pelo próprio sistema nervoso, sendo o que permite ao homem realizar prognósticos e tomar decisões complexas, "por ele não lidar mais com 'dados brutos', mas sim com dados já elaborados [...]"11.

O Direito, então, desenvolve-se reagindo apenas aos seus próprios impulsos, embora estimulado por "irritações" provindas do ambiente social. "Mesmo as mais poderosas pressões só serão levadas em conta e elaboradas juridicamente a partir da forma como aparecem nas 'telas' internas, onde se projeta as construções jurídicas da realidade (rechtlichen Wirklichkeitskonstruktionen). Nesse sentido, as grandes evoluções sociais 'modulam' a evolução do Direito, que, não obstante, segue uma lógica própria de desenvolvimento" 12 .

Nessa altura, vale chamar atenção para o paralelismo que se verifica entre o Direito e a ciência, ambos voltados para o desenvolvimento de segurança e estabilidade no sistema social global, ao darem uma garantia de expectativas, realizando o que Luhmann denomina "dupla seletividade", por fornecerem a possibilidade de uma seleção entre as diversas seleções possíveis do modo como se agir. Há, é claro, diferenças radicais entre "expectativas normativas", garantidas pelo Direito, e "expectativas cognitivas", garantidas pela ciência, já que essas, ao se verem frustradas pela realidade, por estarem preparadas para aprender com ela, devem procurar adaptar-se aos fatos que as frustram, enquanto as primeiras, ao contrário, são concebidas para se manterem "contrafaticamente", isto é, mesmo depois de frustradas.

Os dois modos básicos de expectativas aqui mencionados, porém, não existem absolutamente separados um do outro, como na "Sociologia do Direito" ${ }^{13}$ Luhmann parecia colocá-los. Em "Sistemas Sociais" (Soziale Systeme), o autor refere que a pesquisa sociológica cada vez mais esclarece como as duas posturas, cognitiva e normativa, se interpenetram ${ }^{14}$. De fato, não se pode deixar de reconhecer na ciência, com sua função tipicamente cognitiva, uma estrutura normativa, responsável pela manutenção, por certo tempo, de conhecimentos adquiridos, que não mais se coadunam com resultados de pesquisas mais acuradas. Nesses casos, normalmente, não se passa simplesmente a sustentar uma tese oposta à que se mostrou falsa, pois a nova tese, muito provavelmente, também se revelará falsa. O que se dá, em geral, é uma mudança da própria estrutura, que a mantinha, possibilitando oferecer uma solução, ao mesmo tempo em que aponta para uma série de novos problemas.

Também o Direito não seria absolutamente imutável, já que para realizar a sua função social adequadamente tem que, ao mesmo tempo, preservar a integridade do sistema social, evitando mudanças excessivas, e viabilizar as transformações necessárias para evitar sua estagnação - e, consequentemente, seu fim. É por isso que para cumprir sua função normativa dispõe de uma estrutura cognitiva, a qual o permite dar conta, por exemplo, do constante descumprimento de suas normas, ao que poderá reagir não só insistindo em sua aplicação, mas, também, revogando-a e/ ou editando outra, ou mesmo todo um conjunto de outras (exemplo, no Brasil: o Código de Defesa do Consumidor), solucionando problemas e,

\footnotetext{
${ }^{9}$ Cf. LUHMANN, Niklas. Rechtssoziologie. Reinbeck bei Hamburg, 1972. v. I. p. 507, 509 ss. Trad. bras. Sociologia do Direito I. G. Bayer (trad.). Rio de Janeiro, 1983. v. II, p. 40 ss., 104-105, passim, 354 (refere o objeto da ciência do Direito como sendo não a realidade do Direito, mas sim uma "realidade simbólica”).

${ }^{10}$ ROTH, Gerhard. Die entwicklung kognitiver selbstreferentialität in menschlichen gehirn. In: DIRK BAECKER et alli (Ed.). Theorie als passion - Festschrift Luhmann, Frankfurt a. M., 1987, p. 414 ss.

${ }^{11}$ ROTH, Gerhard. Die entwicklung kognitiver selbstreferentialität in menschlichen gehirn. In: DIRK BAECKER et alli (Ed.). Theorie als passion - Festschrift Luhmann, p. 415.

${ }^{12}$ TEUBNER, Gunther. Reflexives recht: entwicklungsmodelle des rechts in vergleichender perspektive. Archiv für Rechts - und Sozialphilosophie, Stuttgart, n. 68, 1982, p. 21. Ver também, do mesmo autor: Substantive and reflexive elements in modern law. Law \& Society Review, Denver, v. 17, n 2, 1983, p. 249.

${ }^{13}$ LUHMANN, Niklas. Trad. bras. Sociologia do Direito I. G. Bayer (trad.). Rio de Janeiro, 1983. v. II, p. 53 ss,, 126 ss.

${ }^{14}$ LUHMANN, Niklas. Soziale systeme. Grundriß einer allgemeinen theorie. 3. ed. Frankfurt a. M., 1987, p. 436 ss., texto e nota 119.
} 
ao mesmo tempo, criando vários outros, potenciais, pelo simples aumento de normas.

Hoje em dia se coloca a questão de saber se não caberia pôr limites a esse processo, o qual se verifica tanto na ciência como no Direito, de oferecer soluções criando outros problemas, demarcando setores em que a pesquisa científica e a regulamentação jurídica não deveriam avançar, evitando causar distúrbios em outros sistemas sociais. Assim, a determinação das condições do possível, comum ao direito enquanto dogmática jurídica e à ciência, da mesma forma como outros "conceitos de disposição", como verificabilidade, falsificabilidade, operacionalidade e decidibilidade, de "conceitos modais"15 passam a assumir conotação deôntica. Fala-se, então, de "desregulamentação da economia", "desjurisdicização de relações íntimas", "freios" à pesquisa da energia atômica e da genética humana etc.

O sistema jurídico, enquanto autopoiético, é fechado, logo, demarca seu próprio limite, autorreferencialmente, na complexidade própria do meio ambiente, mostrando o que dele faz parte, seus elementos, que ele e só ele, enquanto autônomo, produz, ao conferir-lhes qualidade normativa (= validade), e significado jurídico às comunicações que nele, pela relação entre esses elementos, acontecem. No processo evolucionário de diferenciação e reprodução do Direito a teorização sobre o sistema, isto é, sua estrutura cognitiva, é introduzida no sistema, conferindo-lhe a capacidade de auto-observar-se e, com isso, seu caráter autopoiético, pois é pela auto-observação que controla operações de autoprodução. ${ }^{16}$ De importância decisiva, nesse contexto, é a consumação, no sistema do Direito, da evolução ocorrida no sistema da ciência, o qual, como o primeiro, no início da Era Moderna, encontrava-se "alopoieticamente" orientado para um conhecimento transmitido pelas mais diversas fontes, não científicas. A passagem para um sistema autopoiético se dá quando a ciência se estrutura no sentido de permitir a constante aquisição de novos conhecimentos, por ela mesma produzidos, ao invés de ter como objetivo a manutenção de um conhecimento transmitido tradicionalmente. ${ }^{17}$

Também o Direito "emanava" de fontes as mais díspares, tais como o direito romano, glosas deste feitas por jurisconsultos medievais, costumes e práticas judiciárias locais. O conceito mesmo de "fontes do direito", até o presente, é empregado na teoria jurídica, que há de superá-lo, para se firmar enquanto unidade de auto-observação do Direito como sistema autopoiético.

A superação da doutrina das fontes do Direito por uma "teoria dos modelos" é proposta por Miguel Reale ${ }^{18}$, nesse ponto influenciado, como Luhmann, pelo estrutural-funcionalismo de Talcott Parsons ${ }^{19}$. A substituição de um paradigma pelo outro corresponderia, no entender de Reale, a uma atualização do pensamento jurídico com a forma contemporânea de pensar científico, por seu caráter operacional, portador de significação em uma totalidade de sentido, contrastando com o conceito de "fonte jurídica", ligado a uma visão evolucionista, própria da compreensão científica no século XIX. Por isso mesmo, esse conceito tem uma conotação retrospectiva, enquanto o de modelo é prospectivo.

A noção de "fontes do direito", por fim, adquiriu sentido sobretudo "formal", sendo com esse sentido que passou a se ocupar o estudioso do direito, distinguindo-o do seu sentido "material", correspondente aos fatores reais - valores, estruturas de poder, fatos sociais -, determinantes do surgimento das chamadas fontes formais, que seriam aquelas reconhecidas pelo Direito como

\footnotetext{
${ }^{15}$ LUHMANN, Niklas. Die Einheit des Rechtssystems. Rechtstheorie, Berlim, n. 14, 1983, p. 34, texto e nota 30.

${ }^{16}$ Cf. TEUBNER, Gunther. Reflexives recht: entwicklungsmodelle des rechts in vergleichender perspektive. Archiv für Rechts - und Sozialphilosophie, Stuttgart, n. 68, 1982, p. 429. Ver, ainda, sobre as colocações feitas nesse parágrafo, extensamente, LUHMANN, Niklas. Die Einheit des Rechtssystems. Rechtstheorie, Berlim, n. 14, 1983, p. 129 ss., e LADEUR, Karl-Heinz. Perspektiven einer post-modernen Rechtstheorie: zur auseinandersetzung mit Niklas Luhmanns conzept der 'Einheit des Rechtssystems'. Rechtstheorie, Berlim, n. 16, 1985, p. 393 ss., especialmente p. 397-399, bem como, do mesmo autor: Abwägung' - ein neues Rechtsparadigma? Von der einheit der rechtsordnung zur pluralität der rechtsdiskurse. Archiv für Rechts - und Sozialphilosophie, Stuttgart, n. 69, 1983, p. 475-476.

${ }^{17}$ STICHWEH, Rudolf. Die autopoiesis der wissenschaft. In: DIRK BAECKER et alli (Ed.). Theorie als passion - Festschrift Luhmann. Frankfurt a. M., 1987, p. 450-451, 453, 463.

${ }^{18}$ REALE, Miguel. O Direito como experiência - Introdução à Epistemologia Jurídica. São Paulo, 1968, p. 147 ss., especialmente p. 167 ss. e 179 ss.

${ }^{19}$ Neste sentido, MOREIRA, João Baptista. Um estudo sobre a teoria dos modelos de Miguel Reale. São Paulo, Resenha Universitária, 1977 , p. 56.
} 


\subsection{TEORIA SOCIOJURÍDICA NACIONAL}

capazes de gerar Direito, o que nos ordenamentos estatais se confunde com a noção de norma jurídica.

No conceito de modelo jurídico, coerente com sua "Teoria Tridimensional do Direito", Reale inclui já os "motivos determinantes da estrutura normativa" ${ }^{20}$, qual seja a valoração de fatos realizada por sujeitos investidos do poder de realizá-la de forma vinculante para outros, externando-a em uma norma do Direito.

A teoria dos modelos de Reale, por ele apresentada no IV Congresso Internacional de Filosofia Jurídica e Social, em 1970, foi incorporada à perspectiva sistêmica ${ }^{21}$. Para atender à condição cognitiva necessária à autorreflexão e à autoprodução do Direito, porém, os modelos jurídicos devem ser concebidos como modelos internos do sistema, construtores de uma realidade especificamente jurídica, com o que não se coaduna a distinção feita por Reale entre "modelos jurídicos" e "modelos dogmáticos", onde estes últimos seriam modelos "criados" pela teoria do direito.

O sistema jurídico como um todo, para a teoria de sistemas autopoiéticos, é uma criação dos membros da sociedade em interação comunicativa. Os modelos jurídicos que permitem definir o que é um contrato ou uma sociedade comercial para o Direito se enraízam em uma percepção jurídica peculiar da realidade social, moldada, basicamente, pelos que se dedicam à produção de conhecimento sobre o Direito. A autonomia do Direito, portanto, resulta não apenas da autoprodução de suas normas, mas também da autoconstituição de figuras jurídico-dogmáticas, que permitam reformular, em termos especificamente jurídicos, a percepção de uma problemática extrajurídica (econômica, política, moral etc.). Assim, para Teubner ${ }^{22}$, "(T)hese perceptions differ significantly from our day-to-day understanding of these phenomena as well as from so- ciological or economic theories. The legal system develops certain specific social constructions of reality (BERGER and LUCKMANN, 1966) in order to decide social conflicts under the guidance of legal norms. In creating its own reality from the perspective imposed by the exigencies of conflict resolution, the legal systems abstracts heighly selective models of the world, thereby neglecting many politically, economically, and socially 'relevant' elements".23

O Direito, para se autoproduzir, necessita, obviamente, como todo sistema, de elementos do seu meio ambiente ou circundante (Umwelt, nos termos empregados por Luhmann, sendo esta a distinção fundamental de toda teoria, a saber, a de sistema e o que não é sistema, esse entorno). Para que haja um ordenamento jurídico regulando condutas, há que se ter não só normas para fornecer essa regulamentação, como também condutas que estabeleçam essas normas, e em sendo esse ordenamento autônomo, as condutas que estabelecem novas normas já são, elas próprias, reguladas por normas anteriores. Atento a essa circunstância, presente nos ordenamentos jurídicos dos Estados de Direito contemporâneos, Hans Kelsen ${ }^{24}$, em sua influente "Teoria Pura do Direito" (Reine Rechtslehre), introduz a diferença entre um "sistema estático" e outro "dinâmico", na ordem jurídica, onde no primeiro haveria "normas regulando condutas" e no outro "condutas produzindo normas", observando normas que as regulam, (auto)regulando essa produção normativa. As condutas, então, que produzem as normas são elementos do meio, provenientes de outro sistema, sistema condutual (Handlungssystem), mas adquirem significado jurídico objetivo quando a ela se reporta uma norma jurídica, e esse significado pode ser o de que outra norma foi produzida. Assim, exemplificando com Kelsen ${ }^{25}$, tem-se que, em uma

\footnotetext{
${ }^{20}$ REALE, Miguel. O Direito como experiência - Introdução à Epistemologia Jurídica, p. 172.

${ }^{21}$ Ver LUHMANN, Niklas. Sociologia do Direito I. G. Bayer (trad.). Rio de Janeiro, 1983. v. II, p. 97, texto e nota 107; TEUBNER, Gunther. Generalklauseln als sozio-normative modelle. In: LÜDERSSEN (Ed.). Generalklauseln als gegenstand der sozialwissenschaften. Baden-Baden, 1978. p. 13 ss.; TEUBNER, Gunther. Reflexives recht: entwicklungsmodelle des rechts in vergleichender perspektive. Archiv für Rechts - und Sozialphilosophie, Stuttgart, n. 68,1982 , p. $55-56$, nota 150.

${ }^{22}$ TEUBNER, Gunther. Substantive and reflexive elements in modern law. Law \& Society Review, Denver, v. 17, n 2, 1983, p. 279

${ }^{23}$ Cf. TEUBNER, Gunther. Jurisdification: concepts, aspects, limits, solutions. In: 440-441.

${ }^{24}$ KELSEN, Hans. Reine Rechtslehre. 2. ed. Wien, 1961.

${ }^{25}$ KELSEN, Hans. Reine Rechtslehre, p. 2.
} 


\subsection{TEORIA SOCIOJURÍDICA NACIONAL}

sala pessoas se reúnem, discursam, algumas (a maioria) levantam suas mãos, outras ficam impassíveis: olhando "de fora", eis o que acontece em uma Câmara de Deputados. "De dentro" do sistema jurídico, porém, tem-se que uma lei foi votada, de acordo com o procedimento previsto na Constituição, nos Estatutos da Câmara etc., e o Direito foi (auto)produzido.

Há uma organização (jurídica) produzindo os elementos (atos jurídicos, normas jurídicas) de sua estrutura (jurídica), pelas relações que se estabelecem entre eles, formando unidades (as "leis federais" de um país, as normas de direito privado etc.). O sistema (jurídico) é autopoiético e diferenciado de outros, pois estabelece conexões que conferem sentido (jurídico) a condutas referidas, assim, umas às outras e delimitadas, no sistema, em relação ao ambiente.

Para que o Direito tenha chegado a se constituir como sistema autopoiético foi de essencial importância a formação de determinadas unidades, às quais, de um modo geral, pode-se denominar "procedimentais". Um dos grandes méritos de Kelsen foi ter voltado a atenção para o seu estudo, em sua teoria do direito. ${ }^{26}$ Elas são formadas por aquelas normas que Herbert L. A. Hart $^{27}$ qualifica de "normas secundárias", por serem normas que se reportam a outras normas, seja para determinar se uma norma pertence ao sistema ("normas de reconhecimento"), seja para disciplinar, como para retirar ou acrescentar norma ao sistema ("normas de câmbio"), seja para regular a aplicação de norma em um caso concreto ("normas de julgamento").

Nesse contexto, entende-se melhor porque, na já aludida obra final de Luhmann sobre o sistema do direito, mais à frente da passagem antes referida, ele sugira que a distinção entre direito material e processual resulte no que, em termos empregados por ele, mas não nesse contexto, podemos considerar um equivalente funcional ao que em um momento histórico anterior representou a doutrina das fontes do direito, como ponto de partida para a realização das operações de um sistema jurídico.

O Direito, em uma sociedade com alta diferenciação funcional de seus sistemas internos, mantém-se autônomo frente aos demais sistemas, como aqueles da moral, da economia, da política, da ciência, na medida em que continua operando com seu próprio código e não por critérios fornecidos por algum daqueles outros sistemas. Ao mesmo tempo, sem que seus componentes percam seu conteúdo especificamente jurídico para adotar outros, de natureza moral, política, econômica etc., o sistema jurídico há de realizar o seu acoplamento estrutural com outros sistemas sociais, para o que desenvolve cada vez mais procedimentos de reprodução jurídica, procedimentos legislativos, administrativos, judiciais, contratuais. Penso que o significado do acoplamento estrutural entre os diversos sistemas sociais pode ser iluminado por uma formulação de Luhmann em obra anterior à "virada" para o paradigma autopoiético, quando já falava da necessidade de cada um desses sistemas se coordenarem para cumprirem a função comum de reduzir a complexidade do meio social, quando então os diversos sistemas, perseguindo cada um a finalidade que lhe fosse específica, "neutralizaria" o seu campo de atuação. O modo como coordenariam essa "divisão de trabalho" seria pela transformação de meio (Mittel) para um sistema do que era o fim (Zweck) específico de outro, de modo que "para um ficaria no centro das atenções o que para o outro não passava de um fenômeno secundário, quase imperceptível (kaum noch wahrnehmbare Randerscheinung)" 28 .

Tais procedimentos são instituídos para (auto)regulação e (auto)controle na fundamentação de algum dos possíveis conteúdos das normas jurídicas, que seja adequado a exigências sociais de racionalidade, participação democrática, pluralismo de valores, eficiência econômica etc. Os procedimentos jurídicos é que haverão de ser estruturados atendendo já a essas exigências, pois não é mais possível, nas sociedades hipercomplexas de hoje, que o Direito se limite a con-

\footnotetext{
${ }^{26}$ Nesse sentido: LUHMANN, Niklas. Legitimation durch Verfahren. Opladen, 1969, p. 11, nota 2.

${ }^{27}$ HART, Herbert L. A. The concept of law. London, 1961, p. 77 ss.

${ }^{28}$ LUHMANN, Niklas. Zweckbegriff und systemrationalität. Über die funktion von zwecken in sozialen systemen. 5. ed. Frankfurt am Main, 1991, p. 273.
} 
sagrá-las formalmente, nem se pode pretender que ele as realize plenamente. ${ }^{29}$

É nesse contexto que a Constituição revela-se como grande responsável pelo acoplamento estrutural entre os (sub)sistemas jurídico e político $^{30}$, jurisdicizando relações políticas e mediatizando juridicamente interferências da Política no Direito, ao condicionar transformações nas estruturas de poder a procedimentos de mutação previstos constitucionalmente. Os direitos fundamentais tornam-se, assim, o que há de mais importante a ser consagrado na Constituição de um Estado Democrático, com sua multidimensionalidade, enquanto direitos de liberdade, direitos a prestações (os direitos sociais), direitos à participação na formação da vontade política estatal, direitos de natureza processual etc. ${ }^{31} \mathrm{Ne}$ les acham-se expressos valores integrantes das ideologias as mais diversas, tornando a Constituição que os consagra uma representação fiel ou, ao menos, bastante aproximada da sociedade hipercomplexa que a instituiu. A Constituição, sem se identificar com nenhuma das diversas e, muitas vezes, contraditórias - concepções de mundo vigentes na sociedade e, de certo modo, contemplando-as todas, na forma de direitos fundamentais das mais diversas "gerações", viabiliza a continuidade da diferenciação sistêmica e a intensificação das comunicações intra e intersistêmicas ${ }^{32}$. Aqui, penso ser mais adequado falar em "dimensões" de direitos, ao invés de "gerações", pois a partir da terceira geração eles se mostraram como "transgeracionais", já que a realização plena dos de primeira geração pressupõe a daqueles de segunda e terceira, e assim por diante. ${ }^{33}$

Recolocando agora o centro de nossas atenções no Judiciário, com o enfoque da teoria sistêmica, tem-se que Luhmann ${ }^{34}$ aponta para a dependência que há entre Legislativo e Judiciário, quando se estabelece, como no já mencionado art. 97 da Constituição alemã, que, verbis, "os Juízes são independentes e estão sujeitos apenas à lei”, o que, se de um lado lhes retiraria a atribuição política de fornecer as pautas de conduta na sociedade, de outro, por não poderem ser responsabilizados politicamente por suas decisões, tornam-se livres para operar com o Direito a partir do próprio Direito, transformando, pela interpretação, os institutos em que se assentam as bases sociais: propriedade, contrato, família etc.

Por ser o Judiciário a única unidade que opera apenas com elementos do próprio sistema jurídico - o qual, ao prever a proibição do non liquet, força-o a sempre dar um enquadramento jurídico a quaisquer fatos e comportamentos que sejam levados perante ele -, postula-se que essa unidade ocuparia o centro do sistema jurídico, ficando tudo o mais em sua periferia, inclusive o Legislativo, em uma região fronteiriça com o sistema político. Eis o "paradoxo da transformação da coerção em liberdade”, uma vez que o juiz se acha vinculado às leis, mas não à legislação, que

\footnotetext{
${ }^{29}$ Cf. ALEXY, Robert. Rechtssystem und praktische Vernunft. Rechtstheorie, Berlim, n. 18, 1987; DENNINGER, Erhard. Goverment assistance in the exercise of basic rights (Procedure and Organization). In: JOERGES, Ch.; TRUBEK, D.M. (Ed.). Critical legal thought: an american-german debate. Baden-Baden, 1989; HABERMAS, Jürgen. Wie ist Legitimität durch Legalität möglich? Kritische Justiz, Baden-Baden, n. 20, 1987; HABERMAS, Jürgen. Geltung und Faktizität. Frankfurt am Main, 1992; HABERMAS, Jürgen. Die Einbeziehung des Anderen. Frankfurt am Main, 1996; LUHMANN, Niklas. Rechtssoziologie. Reinbeck bei Hamburg, 1972. v. I, p. 171 e Trad. bras. Sociologia do Direito I. G. Bayer (trad.). Rio de Janeiro, 1983. v. II, p. 207 ss.; LUHMANN, Niklas. Das recht der gesellschaft. Frankfurt am Main, 1993, p. 344 ss., 558; TEUBNER, Gunther. Reflexives recht: entwicklungsmodelle des rechts in vergleichender perspektive. Archiv für Rechts - und Sozialphilosophie, Stuttgart, n. 68, 1982, p. 26; TEUBNER, Gunther. Substantive and reflexive elements in modern law. Law \& Society Review, Denver, v. 17, n 2, 1983, p. 254 ss.; 1984: 109 ss.; TEUBNER, Gunther. Jurisdification: concepts, aspects, limits, solutions. In:___ (Ed.) Jurisdification of social spheres. Berlin/New York, 1987, p. 441 ss.; WIETHÖLTER, Rudolf. Entwicklung des rechtsbegriffes. Jahrbuch für Rechtssoziologie und Rechtstheorie, n. 8, 1982; GUERRA FILHO, Willis S. O princípio constitucional da proporcionalidade. In: (Org.). Ensaios de teoria constitucional. Fortaleza: Imprensa Universitária-UFC, 1989, p. 22 ss; GUERRA FILHO, Willis S. O direito como sistema autopoiético. Revista Brasileira de Filosofia, São Paulo, n. 163, 1991, p. 195 e, em geral, GUERRA FILHO, Willis S. Autopoiese do Direito na Sociedade Pós-Moderna. Porto Alegre: Livraria do Advogado, 1997.

${ }^{30}$ NEVES, Marcelo. Entre subintegração e sobreintegração: a cidadania inexistente. Dados - Revista de Ciências Sociais, Rio de Janeiro, v. 37, n. 2, 1994, p. 61 ss.

${ }^{31}$ GUERRA FILHO, Willis S. A dimensão processual dos direitos fundamentais. In: Direito constitucional. Congresso Internacional de Direito Constitucional, Administrativo e Tributário, Recife, Brasília, 1996.

${ }^{32}$ BONAVIDES, Paulo. Curso de direito constitucional. 5. ed. São Paulo: Malheiros, 1994, p. 516 ss.

${ }^{33}$ Cf., em apoio, NEVES, Marcelo. Entre subintegração e sobreintegração: a cidadania inexistente. Dados - Revista de Ciências Sociais, Rio de Janeiro, v. 37 , n. 2, 1994, p. 71 ss.

${ }^{34}$ LUHMANN, Niklas. Verfassung als evolutionäre errungenschaft. Rechtshistorisches Journal, Frankfurt am Main, n. 9, 1990; LUHMANN, Niklas. Das recht der gesellschaft. Frankfurt am Main, 1993, p. 297 ss.
} 
é sempre objeto de sua interpretação, inclusive a norma que o vincula à lei, levando em conta textos com autoridade superior como aquele da Constituição. "Quem se vê coagido à decisão e, adicionalmente, à fundamentação de decisões, deve reivindicar para tal fim uma liberdade imprescindível para construção do Direito" ${ }^{35}$. É uma tal unidade que garante a autonomia do sistema e a sua "autorreprodutibilidade" (= autopoiesis) ${ }^{36}$, , para o que recebem o apoio imprescindível de uma "unidade cognitiva", a chamada "doutrina”, que não apenas é responsável pela sofisticação da hermenêutica jurídica, como fornece interpretações passíveis de serem adotadas pelo Judiciário e, assim, introduzidas no sistema jurídico normativo. Afinal, a doutrina ou dogmática jurídica, como sustenta Luhmann em trabalho já clássico, "Sistema Jurídico e Dogmática Jurídica”, caracteriza-se, igualmente, por constituir uma liberdade de pensamento sob a aparência de vinculação a conceitos dogmatizados, inquestionáveis, mas que, na verdade, tanto podem oferecer respostas como tornarem-se instrumento de questionamentos, enquanto formas cujo conteúdo e, logo, também o seu sentido podem sempre ser atualizados, para atender às exigências sociais de segurança ou, ao menos, da "insegurança suportável" de um problema para o qual se pode oferecer uma solução, encerrando-o com uma decisão. ${ }^{37}$ Daí se poder falar, foucaultianamente, em uma "unidade de discurso" entre as práticas discursivas da academia e do Judiciário. ${ }^{38}$

Defendemos que o princípio da proporcionalidade é capaz de dar um "salto hierárquico" (hierarchical loo $p^{39}$ ), ao ser extraído do ponto mais alto da "pirâmide" normativa para ir até a sua "base", onde se verificam os conflitos concretos, validando as normas individuais ali produzidas, na forma de decisões administrativas, judiciais etc. Essa forma de validação é tópica, permitindo atribuir um significado diferente a um mesmo conjunto de normas, a depender da situação a que são aplicadas. É esse o tipo de validação requerida nas sociedades hipercomplexas da pós-modernidade, que se conectam na (e à) sociedade mundial. Nela(s) se misturam criação (legislação) e aplicação (jurisdição e administração) do Direito, tornando a linearidade do esquema de validação kelseneano pela referência à estrutura hierarquicamente escalonada do ordenamento jurídico em circularidade, com o embricamento de diversas hierarquias normativas, as "tangled hierarchies", ou seja, hierarquias embricadas (heterarquicamente, pode-se dizer) da teoria sistêmica ${ }^{40}$. Concretamente, isso significa que assim como uma norma ao ser aplicada mostra-se válida pela remissão a princípios superiores insculpidos na Constituição, esses princípios validam-se por serem referidos na aplicação daquelas normas. Fecham-se, assim, autopoiética e, circularmente, o Direito.

\section{REFERÊNCIAS}

ALEXY, Robert. Rechtssystem und praktische Vernunft. Rechtstheorie, Berlim, n. 18, 1987.

BONAVIDES, Paulo. Curso de direito constitucional. 5. ed. São Paulo: Malheiros, 1994.

DENNINGER, Erhard. Goverment assistance in the exercise of basic rights (Procedure and Organization). In: JOERGES, Ch.; TRUBEK, D.M. (Ed.). Critical legal thought: an american-german debate. Baden-Baden, 1989.

GUERRA FILHO, Willis S. O princípio constitucional da proporcionalidade. In: ___ (Org.). Ensaios de teoria constitucional. Fortaleza: Imprensa Universitária-UFC, 1989.

O direito como sistema autopoiético. Revista Brasileira de Filosofia, São Paulo, n. 163,

\footnotetext{
${ }^{35}$ LUHMANN, Niklas. Das recht der gesellschaft. Frankfurt am Main, 1993, p. 297 ss.

${ }^{36} \mathrm{Cf}$. JACOBSON, Arthur J. Autopoietic law: the new science of Niklas Luhmann. Michigan Law Review, n. 87, 1989; GUERRA FILHO, Willis S. O direito como sistema autopoiético. Revista Brasileira de Filosofia, São Paulo, n. 163, 1991.

${ }^{37}$ Cf. LUHMANN, Niklas. Die Einheit des Rechtssystems. Rechtstheorie, Berlim, n. 14, p. 29 ss., 40, 102.

${ }^{38}$ RUBIN, Edward L. The practice and discourse of legal scholarship. Michigan Law Review, Lincoln, v. 86, n. 6, 1988.

${ }^{39}$ HOFSTADTER, D. I am a strange loop. New York, 2007.

${ }^{40}$ Ver, v.g., NEVES, Marcelo. A constitucionalização simbólica. São Paulo, Acadêmica, 1994, p. 66 ss, texto e notas 71 e 78.
} 
1991.

. A dimensão processual dos direitos fundamentais. In: Direito constitucional. Congresso Internacional de Direito Constitucional, Administrativo e Tributário, Recife, Brasília, 1996.

Autopoiese do Direito na Sociedade Pós-Moderna. Porto Alegre: Livraria do Advogado, 1997.

HABERMAS, Jürgen. Wie ist Legitimität durch Legalität möglich? Kritische Justiz, Baden-Baden, n. 20, 1987.

Geltung und Faktizität. Frankfurt am Main, 1992.

.Die Einbeziehung des Anderen. Frankfurt am Main, 1996.

HART, Herbert L. A. The concept of law. London, 1961.

HESSE, Konrad. Grundzüge des verfassungsrechts der bundesrepublik deutschland. 14th. ed. Heidelberg, 1984.

HOFSTADTER, D. I am a strange loop. New York, 2007.

JACOBSON, Arthur J. Autopoietic law: the new science of Niklas Luhmann. Michigan Law Review, n. 87, 1989.

JOERGES, Christian. Politische Rechtstheorie and critical legal studies: points of contact and divergencies. In: ; TRUBEK, D.M. (Ed.). Critical legal thought: an american-german debate. Baden-Baden, 1989.

KELSEN, Hans. Reine Rechtslehre. 2. ed. Wien, 1961.

KENNEDY, Duncan. The role of law in economic thought: essays on the fetishism of commodities. The American University Law Review, n. 34, 1985.
LADEUR, Karl-Heinz. Abwägung' - ein neues Rechtsparadigma? Von der einheit der rechtsordnung zur pluralität der rechtsdiskurse. Archiv für Rechts - und Sozialphilosophie, Stuttgart, n. 69, 1983.

Perspektiven einer post-modernen $\mathrm{Re}$ chtstheorie: zur auseinandersetzung mit Niklas Luhmanns conzept der 'Einheit des Rechtssystems. Rechtstheorie, Berlim, n. 16, 1985.

LUHMANN, Niklas. Legitimation durch Verfahren. Opladen, 1969.

Rechtssoziologie. Reinbeck bei Hamburg, 1972. v. I. [Trad. Bras]. Sociologia do Direito I. G. Bayer (trad.). Rio de Janeiro, 1983. v. II.

. Die Einheit des Rechtssystems. Rechtstheorie, Berlim, n. 14, 1983.

Sistema juridico y dogmatica juridica. Trad. Ignacio de Otto Prado. Madrid, 1983.

Soziale systeme. Grundriß einer allgemeinen theorie. 3. ed. Frankfurt a. M., 1987.

. Verfassung als evolutionäre errungenschaft. Rechtshistorisches Journal, Frankfurt am Main, n. 9, 1990.

Die stellung der gerichte im rechtssystem. Rechtstheorie, Berlin, n. 21, 1990.

. A posição dos tribunais no sistema jurídico. AJURIS, Porto Alegre, n. 49, 1990.

Die Geltung des Rechts. Rechtstheorie, Berlin, n. 22, 1991.

Zweckbegriff und systemrationalität. Über die funktion von zwecken in sozialen systemen. 5. ed. Frankfurt am Main, 1991.

Das recht der gesellschaft. Frankfurt am Main, 1993. 
Die religion der gesellschaft. In: KEISERLING, A. (Ed.). Frankfurt am Main, 2002. MOREIRA, João Baptista. Um estudo sobre a teoria dos modelos de Miguel Reale. São Paulo, Resenha Universitária, 1977.

NEVES, Marcelo. Entre subintegração e sobreintegração: a cidadania inexistente. Dados - Revista de Ciências Sociais, Rio de Janeiro, vl. 37, n. 2, 1994.

A constitucionalização simbólica. São Paulo, Acadêmica, 1994.

REALE, Miguel. O Direito como experiência Introdução à Epistemologia Jurídica. São Paulo, 1968.

ROTH, Gerhard. Die entwicklung kognitiver selbstreferentialität in menschlichen gehirn. In: DIRK BAECKER et alli (Ed.). Theorie als passion - Festschrift Luhmann, Frankfurt a. M., 1987.

RUBIN, Edward L. The practice and discourse of legal scholarship. Michigan Law Review, Lincoln, v. 86, n. 6,1988 .

STICHWEH, Rudolf. Die autopoiesis der wissenschaft. In: DIRK BAECKER et alli (Ed.). Theorie als passion - Festschrift Luhmann. Frankfurt a. M., 1987.

TEUBNER, Gunther. Generalklauseln als sozio-normative modelle. In: LÜDERSSEN (Ed.). Generalklauseln als gegenstand der sozialwissenschaften. Baden-Baden, 1978.

Reflexives recht: entwicklungsmodelle des rechts in vergleichender perspektive. Archiv für Rechts - und Sozialphilosophie, Stuttgart, n. 68, 1982.

Substantive and reflexive elements in modern law. Law \& Society Review, Denver, v. 17, n 2, 1983.

. Das regulatorische trilemma. Quaderni Fiorentini per la storia del pensiero giuridico mo- derno, Firenze, n. 13, 1984.

. Autopoiesis in law and society: a rejoinder to Blakenburg. Law \& Society Review, Denver, n. 18, 1984.

Jurisdification: concepts, aspects, limits, solutions. In:___ (Ed.) Jurisdification of social spheres. Berlin/New York, 1987.

TRUBEK, David M. Back to the future: the short, happy life of the law and society movement. Florida State University Law Review, Miami, n. 18, 1990.

WIETHÖLTER, Rudolf. Entwicklung des rechtsbegriffes. Jahrbuch für Rechtssoziologie und Rechtstheorie, n. 8, 1982.

\section{Recebido em: 08/08/2014}

Aprovado em: 08/11/204 